Winfried Schrammek (Leipzig)

\title{
Zum Gedenken an Frieder Zschoch (1932-2016)
}

Gotthold Frieder Zschoch, geboren am 30. März 1932 in Großenhain, plötzlich gestorben am 3. März 2016 in Leipzig, war „Pfarrerssohn“. Dies charakterisierte einerseits seine aufrichtige, christlich überzeugte und hilfsbereite Persönlichkeit, führte andererseits in schwerer Zeit zu „gesellschaftlicher“ Zurückhaltung gegenüber seinem klaren Denken, seiner tiefgegründeten Bildung. Die von Frieder Zschoch während des Volksaufstandes am 17. Juni 1953 geblasenen Trompetensignale deuten dies an, sie verursachten beinahe seine Exmatrikulation an der Universität Leipzig, dann aber die Ablehnung seiner vorgesehenen Anstellung am Musikinstrumenten-Museum.

Nach abgeschlossenem Studium der historischen Musikwissenschaft in Leipzig (Serauky, Wolff, Eller), der systematischen Musikwissenschaft in Berlin (Dräger) sowie der Germanistik fand er nach einer Honorartätigkeit beim Hofmeister-Verlag 1954 eine Lektoratsanstellung beim Deutschen Verlag für Musik in Leipzig und war dort seit 1972 als Leiter des „Lektoratsbereichs Erbe/Gesamtausgaben“. „Wenn die Neue Bach-Ausgabe und die Hallische Händel-Ausgabe 40 Jahre deutscher Teilung als einige der ganz wenigen gesamtdeutschen Editionsunternehmungen heil überstanden haben, so ist dies ganz zweifellos als eines seiner persönlichen Verdienste seinem Ideenreichtum, seinem Arbeitseifer und auch seinem puren physischen Einsatz zu verdanken" (Dietrich Berke, Bärenreiter-Verlag). Noch im Rentenalter war Frieder Zschoch an den grundlegenden Vorarbeiten für die Neuausgabe von Händels Giulio Cesare tätig.

Als unbestechlicher Wissenschaftler und exakter Kenner der deutschen Sprache stand er stets freundlich, ja selbstlos den Autoren gegenüber. Bereits 1955 wurde er vom Vorstand der Gesellschaft für Musikforschung zum Geschäftsführer der Zweigstelle Leipzig berufen. Der von ihm mitveranstaltete Musikwissenschaftliche Kongress 1966 in Leipzig wurde zum denkwürdigen Ereignis, da 1968 Kulturfunktionäre der DDR das Ende der Gesellschaft für Musikforschung in der DDR verfügten. „Mit großem persönlichem Einsatz, die Gefährdung durch das herrschende System nicht achtend, tat Frieder Zschoch alles Menschenmögliche, um größeren Schaden von der Gesellschaft für Musikforschung abzuwenden. Zum Dank ernannte diese ihn 1993 zu ihrem Ehrenmitglied, eine Anerkennung, die er sichtlich bewegt entgegennahm“ (Hans-Joachim Schulze, Bach-Archiv Leipzig).

Als Mitglied im 1972 gegründeten Wissenschaftlichen Beirat der Kultur- und Forschungsstätte Michaelstein wirkte er bis 1998 in maßgebender Weise. Vorbereitung und Leitung internationaler Konferenzen, Beratung der Konzertpläne, Kontakte zu entsprechenden Forschungseinrichtungen sowie Redaktion und Mitherausgabe der wissenschaftlichen Publikationsreihen gehörten zu seiner Tätigkeit. 1992 wurde er zum Gründungsvorsitzenden des Förderkreises Musikinstrumenten-Museum der Universität Leipzig gewählt.

Frieder Zschoch hat dreimal geheiratet. Schwere Krankheiten nahmen ihm seine Ehefrauen. An seinen Kindern, Enkeln und Urenkeln hatte er jedoch große Freude, zumal hier die musikalischen Begabungen und künstlerischen Leistungen weiterleben. Er liebte anregende freundschaftliche Geselligkeit. Sein Fehlen wird noch sehr lange Zeit schmerzhaft spürbar bleiben. 